\title{
Image Expression and Aesthetic Theory in Hogarth 's Satirical Moralizing Series
}

\author{
Liwen Wei \\ Beijing Royal School, China \\ 1277087983@qq.com
}

\begin{abstract}
As an 18th-century English artist, the grandfather of satire, William Hogarth painted Marriage à-la-mode and A Rake's progress, which are the representative works of his satirical moralising series, ironically criticized the humanity and social issues appealed in 18th century England. In the satirical moralising series, Hogarth mainly expresses his satirical idea through image elements, the description of the characters and details of the plot, therefore readers will be able to understand the painter's intention through the observation of details. This is also consistent with his skills of drawing based on his own aesthetic theory, which reflects his consistent thinking and proves the relevant relationship between image expression and aesthetic theory.
\end{abstract}

Keywords: Hogarth, Satire, Analysis of beauty, Image element.

\section{The Social and Political Background of the Birth of Hogarth's Satirical Paintings}

William Hogarth was an English painter from the 17th to 18th century. He was born on November 10,1697 , in a poor family of teachers near London. When he was 15 years old, his father discovered his talent in painting, and sent him to the engraver Eris Gambo, to which he was apprenticed to learn engraving. During this time Hogarth learned about the city of London and often drew pictures of people or things he was interested in. It wasn't until 1720 that Hogarth began to work alone, becoming a true copperplate etcher. Six years later, he went to the studio of artist Thornhill to learn oil painting techniques, and his experiments with techniques of both styles can often be found in his works: he rubbed oil painting techniques into the creation of engravings, and this particular style of engraving successfully brought him fame. His most influential works were two series of paintings lampooning social problems: A Harlot's progress and A Rake's progress. These two sets of works had a strong impact on the society at that time, which laid the foundation for him being the founder of the English genre painting in the 18 th century.

Hogarth created his satirical moralising series prints in the mid-18th century, right after his early success, and English society had already experienced the Bourgeois Revolution. As a constitutional monarchy with a well-established capitalist system, England not only boom basted their industrials but also stimulated the progress of the whole society by the ample material supply. The rise of capitalism also brought the development of the Enlightenment. Hogarth himself was a representative figure of the radical progressive thought of the Enlightenment, he advocated autonomy and freedom, paid attention to the rights of the people and advocated thorough democratization. The popularity of progressive ideas and the success of the bourgeoisie changed the decadent atmosphere of the old English aristocracy. But by the same time, the rise of the bourgeoisie also led the "mercenary" transition of the society. As a result, many new social ills appeared. Hogarth created his famous satirical moralising series in his early stage based on some of these issues.

On the other hand, before the emergence of the English art school represented by Hogarth in the 18th century, the art world of 17 th century England was in a more turbulent situation, and the development of art in the Bourgeois Revolution was slow. Much of the activity in English painting during this period was dominated by foreign artists such as Jan Van Eyck.

As 18 th century begins, capitalism developed into a relatively mature and stable stage. At this time, some artists tried to get rid of the influence of foreign culture and establish the national painting school belonging to England. The Industrial Revolution also made printing, copperplate etching, and other art techniques comprehensively innovated. During this period, Hogarth and his several sets of 
prints of satirical moralising series successfully added the 18th-century English art world with a fresh power and nationalism it needed. He freed English art world from the long-term monopoly of foreign artists, created the unique satirical painting tone, and truly formed the national painting school belonging to England. There are also those who think he uses negative examples of the upper class to promote the virtues of the middle class 1 .

During the same period, great changes took place in the English literary world. With the rise of the Enlightenment, the number of educated people soared along with the emerge of a great amount of journal literatures. Prose replaced poetry and occupied the dominant position in the literary world, successfully created a space for expressing public social opinions. Another influence brought by the Enlightenment is that it changed people's ideology, successfully push some social problems into people's eyes, also brought the development of realistic novels, such as Robinson Crusoe and Gulliver's travels. This literary trend not only reflects the social contradictions at that time, but also builds the general atmosphere of criticizing the current situation. Hogarth's satirical moralising series are part of that trend.

Hogarth's works were also influenced by other cultures in the same period. The most influential one was the infiltration of Dutch culture into England, also known as the Early Netherlandish painting. Representative artists of Early Netherlandish painting, such as Hieronymus Bosch (representative works: The Garden of Earthly Delights, Seven Deadly Sins or The Table of Wisdom, etc.), Bruegel Pieter (representative works: Hunters in the snow, Farmers' wedding, etc.), influenced Hogarth's creation style. Most of the works of the Dutch humanist artist Bosch satirize or attack the social oppression at that time, reflecting the miserable life of the people at the bottom of society. In contrast, Bruegel satirizes the progressive spirit of class society by using the image of demons in his satiric paints which is also embodied in the prints on moralising series of Hogarth.

However, different from these two people, the characters in Hogarth's works are all human beings rather than demons, reflecting his characteristics as a representative of realism painting. As a progressive scholar with radical critical thoughts, Hogarth's works are just like his character, sharp and straightforward, revealing the decadence in the 18th-century English society. But Hogarth's creation was far cry from the traditional engraving works with a tradition of preachy2. The following will be from Hogarth's satire on the 18th century English upper class to further clarify his important position in the history of English painting.

\section{Image Representation of Satirical Elements in Hogarth's Paintings}

Hogarth's satire of the English upper class of the eighteenth century can be seen in two sets of satirical moralising series prints, Marriage à-la-mode (FIG. 1) and A Rake's progress (FIG. 2). These two sets of prints respectively describe an interest-based marriage in upper class and the depravity of a young man who inherited great wealth.

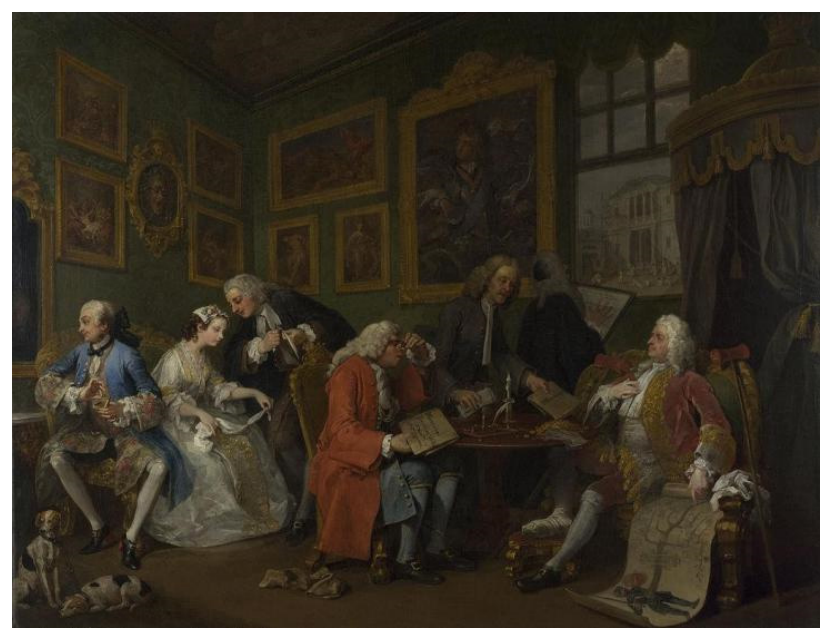

Fig. 1 


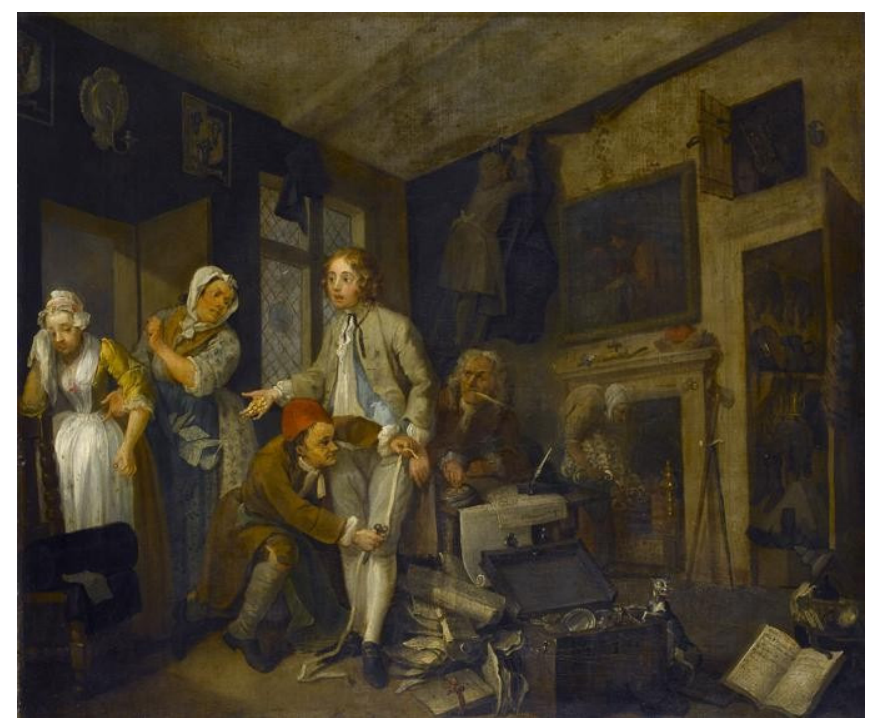

Fig.2

(1) The expression of satirical elements in characterization

Hogarth's satirical elements can be divided into satirical elements in characterization and other satirical elements. Characterization can also be divided into several main categories, such as expression, action, clothing, and so on. In the aspect of expression and action, taking the sixth picture of Marriage à-la-mode (fig.3) as an example, the father's action of grabbing the ring from the dead daughter's hand reflects the prevailing interest in capitalist society at that time. This satirizes the "upper-class" people at that time who was blinded by greed and put money above their relatives' lives. In addition, as shown in the second picture of Marriage à-la-mode (fig.4), the expression depiction plays an important role. The new-married wife in the picture presents in a more open posture. According to Hogarth himself in chapter 6 of The Analysis of Beauty, "a wisp of hair hangs down from the temple," the effect is too seductive to be strictly decent. This is well known to women who are dissolute or underprivileged 3. Hogarth used this gesture to show his wife's infidelity, thus achieving a satirical effect.

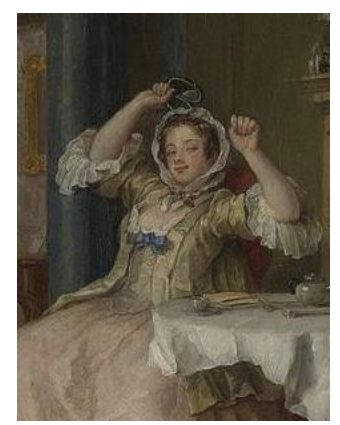

Fig. 3

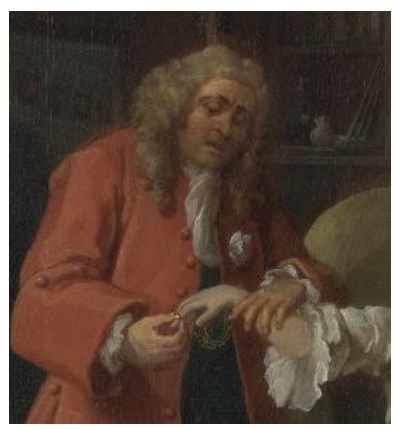

Fig. 4

In the painting series of A Rake's progress, the expression is also the tool used by Hogarth to satirize. In the sixth picture of A Rake's progress (fig. 5), there is smoke in the casino indicating the fire. However, except two of them who notice the smoke, the others are immersed in gambling completely unaware of it. Their faces are full of greed for money. This satirizes the luxury life of the society at that time. In the fifth picture of A Rake's progress (fig.6), Tom, the protagonist, who secretly gazing at the young maid during the wedding with the old rich woman, this can be seen as a represent of those who used marriage as a means of gathering wealth at that time. Hogarth achieved his goal of irony by making the gaze of the protagonist explicit and barefaced. 


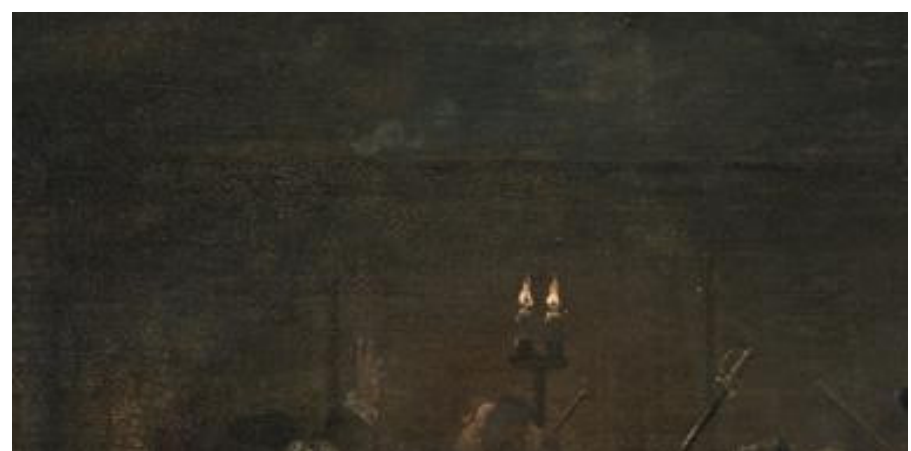

Fig. 5

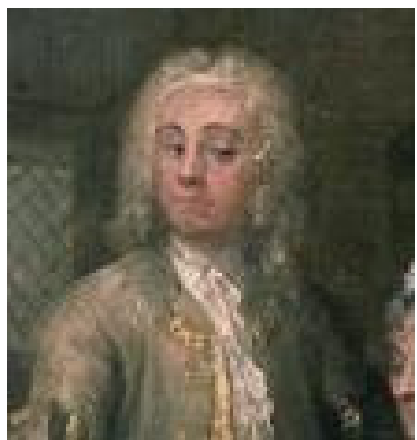

Fig. 6

Such details not only serve as satirical element individually, but also can be combined to achieve the sarcasm. Wigs were a common symbol of wealth and status among English aristocrats in the 18th century. In the fourth picture of A Rake's progress (fig. 7), the lamplighter accidentally pours the oil onto the wig of the protagonist Tom, indicating that his situation has begun to discomfit and less polished than before. In this moment, Tom's golden-tipped walking stick is stolen by passer-by, which also indicates that Tom has lost his wealth and status (fig. 8). In the sixth picture (fig.9), the frustrated Tom throws the wig on the floor, symbolizing that he has heavily addicted to gambling, or that he is no longer part of the upper class and penniless. In the seventh picture of A Rake's progress (fig. 10), Tom's wig is loosely attached to his head and he is wearing the clothes he wore in the sixth picture. The fact that he is bankrupt be clearly shown, but he still tries to maintains his "upper class" identity. In the eighth picture of A Rake's progress (fig. 11), Tom is naked in an insane asylum, with no wig and barely anything on his head - he is completely mad. He lost self-awareness, because the wigs and clothes that symbolizing his wealth and status do not appear in the picture. Hogarth used wig as a symbol to sarcastically map the protagonist's encounter and state.

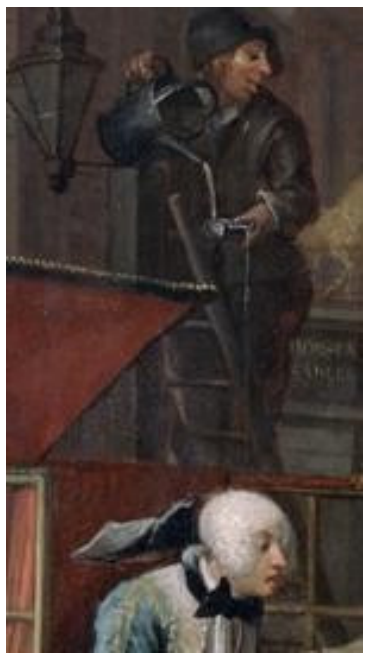

Fig. 7

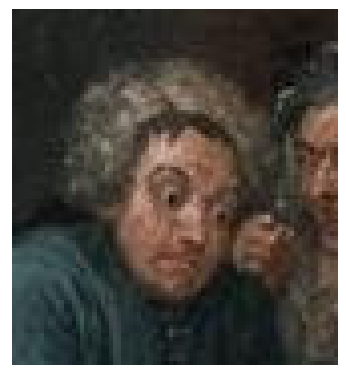

Fig. 10

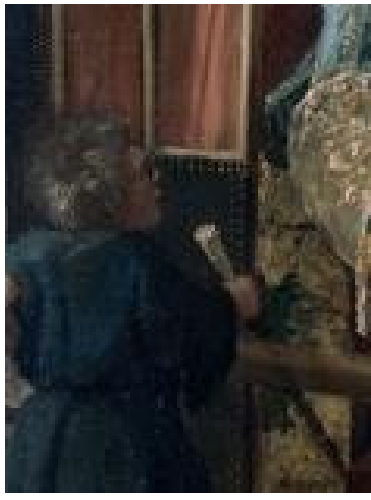

Fig. 8

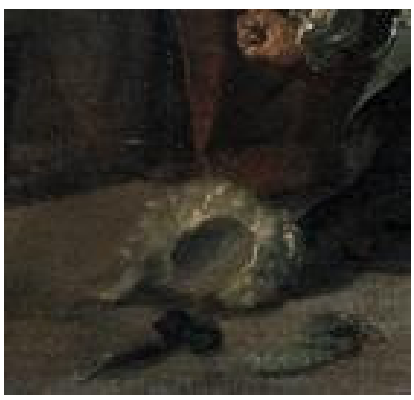

Fig. 9

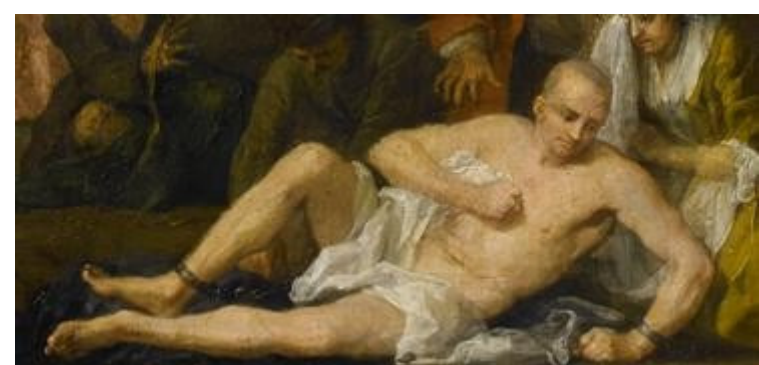

Fig. 11 
Of course, Hogarth's irony can be seen in other elements of clothing, too. In the second picture of A Rake's progress (fig. 12), Tom and the dancers who come to perform are dressed in flamboyant French style. Hogarth himself has said that this "over-grandiose useless style" is what his most disliked. He used this style of dressing, which he himself considered as "most rejected" into several characters, to convey his disgust with the pompous, extravagant habits permeated in the English upper class.

To sum up, in the characterization, the hair that hang down, expression, wig and action all serve as an image element for the satirical theme.

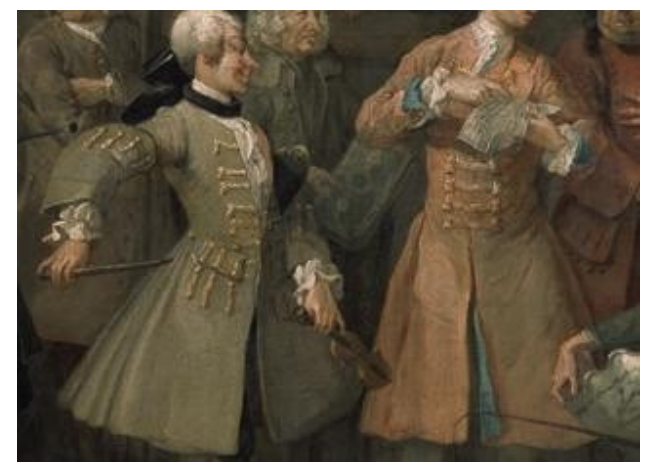

Fig.12

(2) The expression of other satirical elements

In addition to characterization, Hogarth also used other elements in his work, such as animals, for ironic purposes. Dogs are a symbol of loyalty in western culture. In Hogarth's works, dogs often appear as a symbol of marriage. In the first picture of Marriage à-la-mode (fig.13), a pair of dogs are tied up in chains, showing that the marriage of the two protagonists is based on the interests of family, reflecting the phenomenon between families in the upper society at that time. Similarly, in the fifth picture of A Rake's progress(fig.14), there are a pair of dogs tied up, symbolizing how the marriage act as a chain between the characters. The protagonist marries an old rich lady for the sake of interests, therefore one of the dogs has only one eye, just like the old bride. In the second picture of Marriage à-la-mode (fig. 15), a dog pulls out a lady's hat from the husband's pocket, indicate that the newmarried husband has had an affair. The phenomenon that upper-class couple having affairs is also frowned upon by Hogarth.

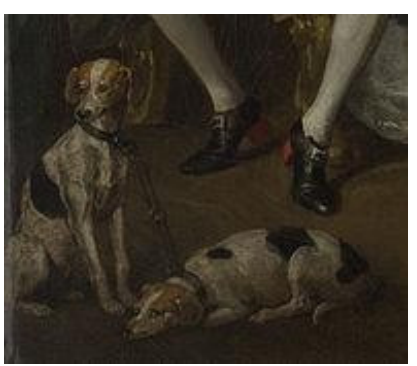

Fig. 13

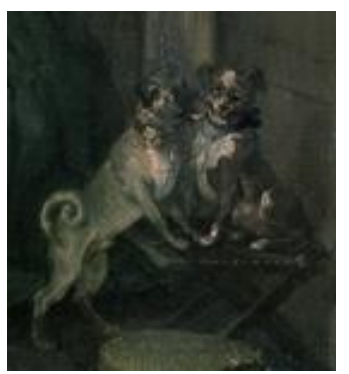

Fig. 14

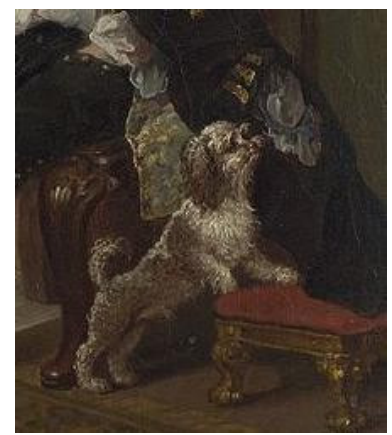

Fig. 15

Hogarth used dog as a symbol to satirize the common phenomenon of marrying for profit in the upper class, also reflecting the social relations of the characters through the situation and actions of dogs.

Hogarth is also good at using allusions from various cultures. In the fourth picture of Marriage à-la-mode (figure 16), an affair takes place between the countess and the lawyer, several allusive paintings hanging on the wall behind them. One is from the biblical story of Lot and his daughters. It tells the story of Lot's two daughters who make their father drunk and incest with him in order to maintain the bloodline after they escape from Sodom (fig.17). The other two, taken from Greek 
mythology (figure 18, 19), Jupiter and Io, and the Rape of Ganymedes, first one depicts Jupiter transform into a cloud of black smoke and flirting with Io, the daughter of river god, and the other tells Zeus turning into a giant eagle and swooping the young beauty Ganymedes from Mount Ida to Mount Olympus as a page boy. In addition to the paintings on the wall, the gnome at the bottom right holds a sculpture of Actaeon from Greek mythology (figure 20) and points to his antlers, representing a man who has been cheated by his wife. All four of these allusions reflect Hogarth's irony about this situation of marriage for the sake of pure interests and their respective affairs.

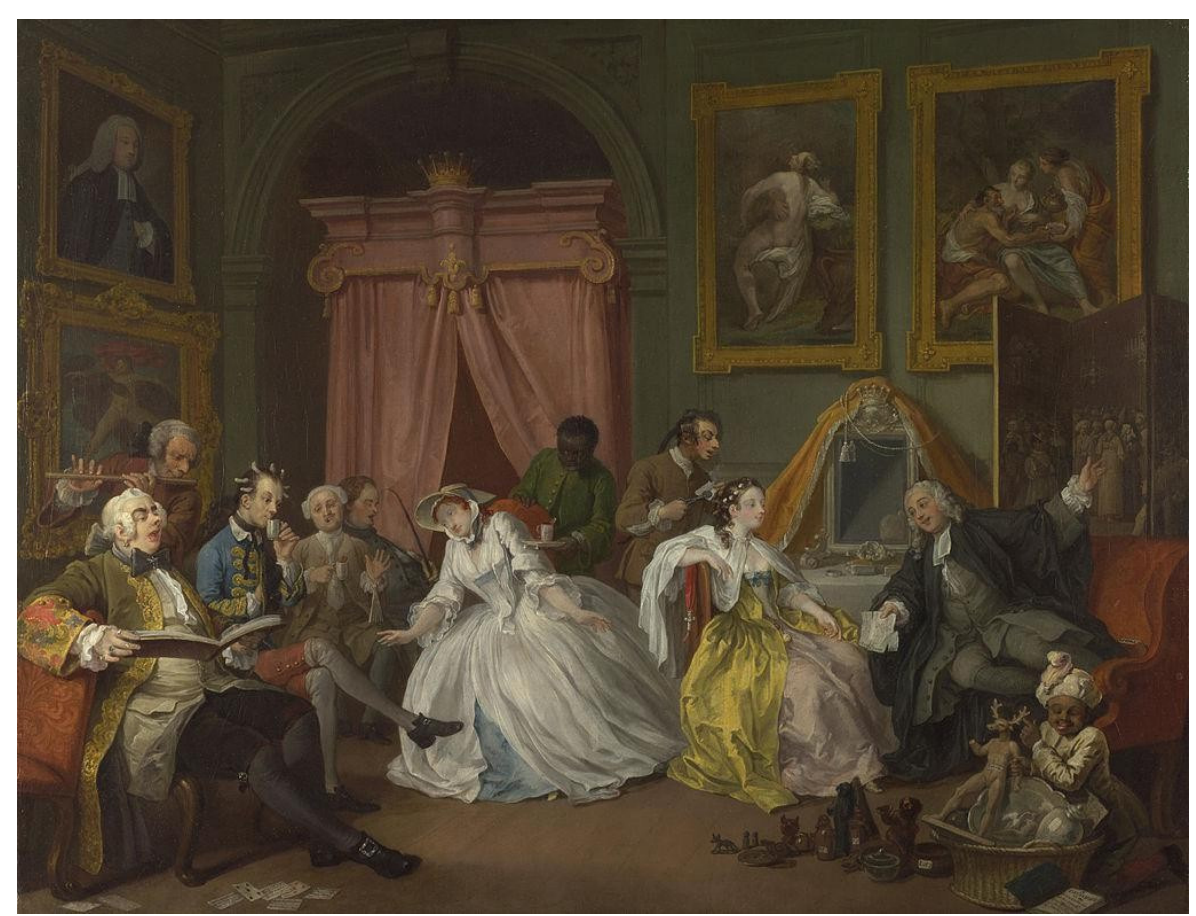

Fig. 16

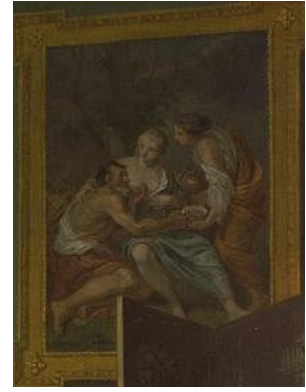

Fig. 17

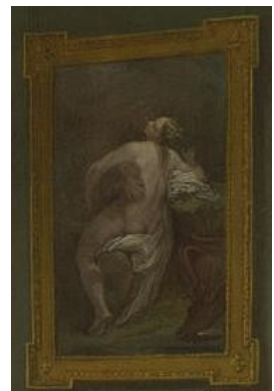

Fig. 18

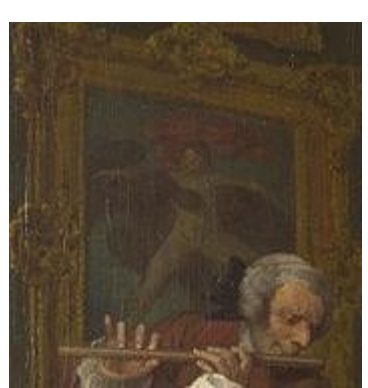

Fig. 19

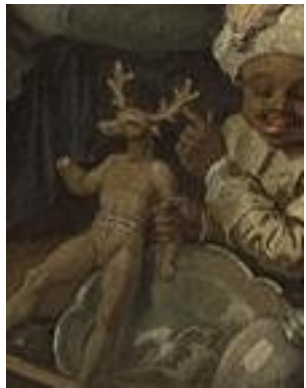

Fig. 20

\section{The Combination of Image Expression and Aesthetic Theory}

(1) The use of lines

Hogarth published The Analysis of Beauty in 1753, which mainly included Hogarth's own theory of visual aesthetics. In chapter 15 the Face, Hogarth cited the Silenus as the counterexample of serpentine. "Human nature," he wrote, "can hardly be represented more debased than in the character of the Silenus. where the bulging-line, No. 7, shown in figure 1, plate 16, rims through all the features of the face, as well as the other parts of his swinish body: whereas in the satyr of. "4. In the eighth scene of A Rake's Progress, the protagonist lying naked on the ground of the lunatic asylum, highly similar to the classic position of the Silenus. Indeed, he employed his theory of visual aesthetics into his works, and achieved the goal of satire by avoiding perfect curves and mapping the character's ugliness with overly elevated or overly smooth lines.

In chapter 16 Attitude, Hogarth argued that " in distortions of pain, as lessened and contracted into plain and parallel lines, to express meanness, awkwardness and submission. 5. For Hogarth, a symbol 
of beauty should be a soft, curved body, which is in the most beautiful gesture. And as the opposite of the serpentine, over intentional posture will appear the character "in distortions". Hogarth found the special significance of the curves 6. In the second picture of A Rake's progress (fig. 21), both the protagonist and the violin-wielding dancer are standing deliberately. Tom's posture, like a straight line lacking in radian, became Hogarth's " unnatural and ridiculous " look. While the dancer deliberately lifts the chest and arms, which does not make him look as graceful as how a dancer should be, but shows his affectations. It can be argued that Hogarth intentionally avoided using what he regarded as the most beautiful serpentine to demonize and satirize characters.

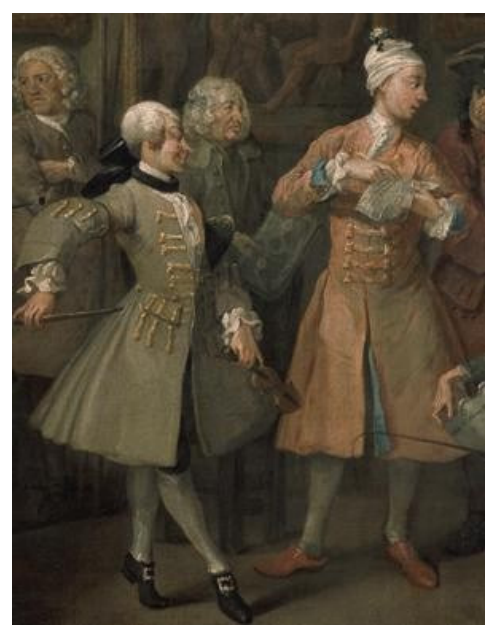

Fig. 21

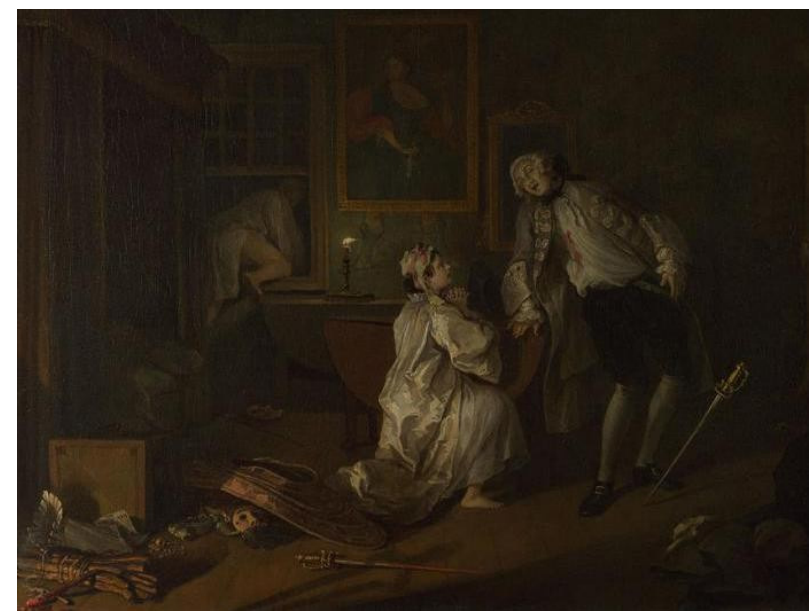

Fig. 22

(2) Construction of picture

In addition to the visual theory directly embodied in the characterization, Hogarth elaborately constructed every element in his works. In chapter 13 Light, Shadow and Color, Hogarth proposed that "Those objects which are intended most to affect the eye, and come most forward to the view, must have large, strong, and smart oppositions," 7 . Hogarth did indeed abide by his aesthetic theory in his work. In the fifth picture of Marriage à-la-mode (fig. 22), the light comes from the lower left corner, and the light directly shines on the countess's white nightdress and the bleeding count's pale face. The two light areas formed a sharp contrast with the rest of the image. Due to the reason that the rest of the picture is in shade, our eyes are drawn directly to the light place, also is where the climax of the story be depicted.

On the contrary, in the seventh picture of A Rake's progress (fig.23), the protagonist disappears into the shadowy area, and the brightest spot is Sarah, Tom's faithful ex-wife, who is faint because of the excessive strike. That doesn't make the protagonist the first thing we see, the audience needs to seek the protagonist. Hogarth managed to create a strong contrast between the protagonist and Sarah. Hiding in the dark is in keeping with Tom's situation of bankruptcy His life is as dark as the shadow he hides in. Hogarth adjust his composition flexibly according to the specific situation, rather than follow without thought. 


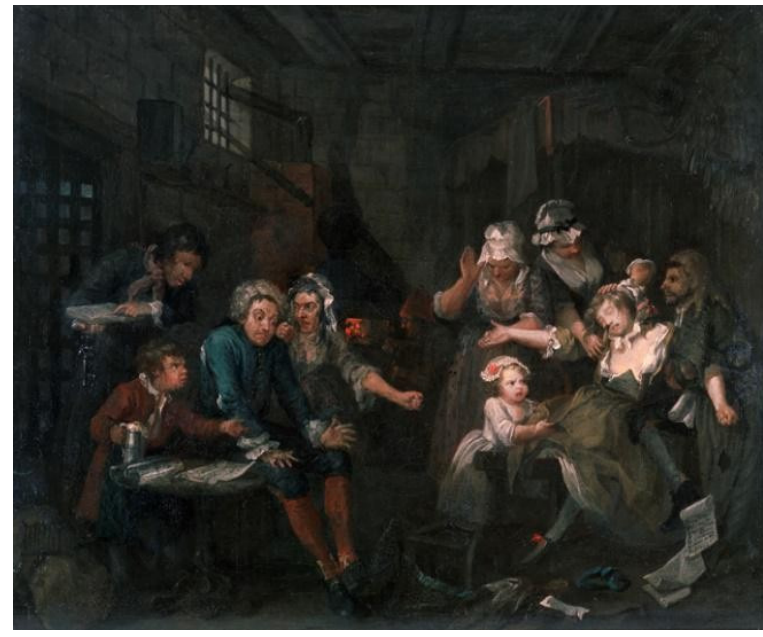

Fig. 23

In chapter 6 Quantity, Hogarth gave an example of monkeys as a combination of two opposing concepts. He said that because the appearance and actions of monkeys are very alike to human beings, this itself is quite laughable. Therefore, putting a monkey in a human dress becomes a banter on human, more of a joke. Both A Rake's progress and Marriage à-la-mode have repeatedly used dogs to imitate human postures. For example, in the first picture of Marriage à-la-mode (fig.15) and the fifth picture of A Rake's progress (fig.14), two pairs of dogs are tied together to imitate the position of the newly-married couple, which endows the animals with human expressions or movements to achieve the banter purpose.

The ideas discussed in The Analysis of Beauty can also find consistent expression in Hogarth's paintings. This indicate that, in the application of the satirical elements we have interpreted before, this kind of detailed description is not what the audience or the researcher makes use of the question to extract and draw attention, but is what the artist had already paid attention to. In summary, Hogarth's image expression and his aesthetic theory reflect and influence each other.

\section{Conclusion}

Hogarth's satirical moralising series of paintings used image elements to express and aesthetic theory to deeply expose and sharply attack some phenomena in the upper-class society of England in 18 th century. Hogarth's bold innovation fund the English national painting school, and his paintings aimed at criticizing the social phenomenon and criticized them. In the aspect of using painting to express social criticism, Hogarth not only paid attention to the expression of aesthetics of the picture form, but also paid attention to the inheritance of traditional painting methods. He expressed satirical elements in the figures' clothing, body, animals, picture layout, story allusions, lines and other aspects. The details highlight the painter's thoughts and the picture is full of dramatic effect. This aspect echoes his aesthetic theory in The Analysis of Beauty, also reflects the mutual influence and combination of theory and practice.

\section{References}

[1]. [US] H.W. Jansen, translated by the combined translation group of art history. Jason art history [M]. World book Shanghai publishing company.2013: 770.

[2]. [US]Francis Lastin, translated by Ma yanyue. From "the prodigal son" to A Rake's progress -- a pioneer in Hogarth's creation [J]. World art.1998(04).

[3]. [UK] William Hogarth, translated by Yang chengyin. The Analysis of Beauty [M]. Guangxi normal university press.2002:83. 
[4]. [UK]William Hogarth, translated by Yang chengyin. The Analysis of Beauty [M]. Guangxi normal university press.2002:211.

[5]. [UK] William Hogarth, translated by Yang chengyin. The Analysis of Beauty [M]. Guangxi normal university press.2002:211.

[6]. [UK] William Hogarth, translated by Yang chengyin. The Analysis of Beauty [M]. Guangxi normal university press.2002:282.

[7]. [UK]William Hogarth, translated by Yang chengyin. The Analysis of Beauty [M]. Guangxi normal university press.2002:186. 